\title{
In-cloud processes of methacrolein under simulated conditions - Part 1: Aqueous phase photooxidation
}

\author{
Yao Liu $^{1}$, I. El Haddad ${ }^{1}$, M. Scarfogliero ${ }^{2}$, L. Nieto-Gligorovski ${ }^{1}$, B. Temime-Roussel ${ }^{1}$, E. Quivet $^{1}$, N. Marchand ${ }^{1}$, \\ B. Picquet-Varrault ${ }^{2}$, and A. Monod ${ }^{1}$ \\ ${ }^{1}$ Universités d'Aix-Marseille I, II et III - CNRS, UMR 6264, Laboratoire Chimie Provence, Equipe: IRA, \\ 3 place Victor Hugo, 13331 Marseilles Cedex 3, France \\ ${ }^{2}$ Laboratoire Interuniversitaire des Systèmes Atmosphériques (UMR 7583), Université Paris, France
}

Received: 22 January 2009 - Published in Atmos. Chem. Phys. Discuss.: 10 March 2009

Revised: 30 June 2009 - Accepted: 1 July 2009 - Published: 28 July 2009

\begin{abstract}
The photooxidation of methacrolein was studied in the aqueous phase under simulated cloud droplet conditions. The obtained rate constant of $\mathrm{OH}$-oxidation of methacrolein at $6^{\circ} \mathrm{C}$ in unbuffered solutions was $5.8( \pm 0.9) \times 10^{9} \mathrm{M}^{-1} \mathrm{~s}^{-1}$. The measured rate coefficient is consistent with $\mathrm{OH}$-addition on the $\mathrm{C}=\mathrm{C}$ bond. This was confirmed by the mechanism established on the study of the reaction products (at $25^{\circ} \mathrm{C}$ in unbuffered solutions) where methylglyoxal, formaldehyde, hydroxyacetone and acetic acid/acetate were the main reaction products. An upper limit for the total carbon yield was estimated to range from 53 to $85 \%$, indicating that some reaction products remain unidentified. A possible source of this mismatch is the formation of higher molecular weight compounds as primary reaction products which are presented in El Haddad et al. (2009) and Michaud et al. (2009).
\end{abstract}

\section{Introduction}

Clouds are present in a large part of the lower atmosphere (60\% of the earth's surface, in the first 4-6 km in altitude). Lelieveld and Crutzen (1991) have shown that clouds exert a major influence, particularly by affecting gas phase concentrations of important tropospheric species such as $\mathrm{O}_{3}$, $\mathrm{NO}_{\mathrm{x}}$ and $\mathrm{HO}_{\mathrm{x}}$. Aqueous cloud droplets provide an efficient medium for liquid phase reactions of water soluble species formed by the photooxidation of reactive organics in the gas

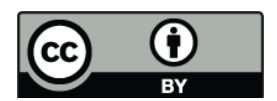

Correspondence to: $\mathrm{Y}$. Liu

(yao.liu@etu.univ-provence.fr) phase (Monod et al., 2005). These compounds readily partition into the droplets, and oxidize further in the aqueous phase to form less volatile organics. Several experimental and modelling studies have demonstrated that aldehydes such as glyoxal, methylglyoxal and glycolaldehyde can form low volatility products such as glyoxylic and oxalic acids as well as larger molecular weight compounds and oligomers by aqueous phase reactions (Warneck, 2003; Altieri et al., 2006, 2008; Carlton et al., 2007). Unlike gas-phase chemistry, the aqueous medium enables formation of new structures (e.g. gem diols) whose functional groups are susceptible to be oxidized during reactions with $\mathrm{OH}$ radical and other oxidants, while the initial C-C bond structures is preserved (Carlton et al., 2007). Differences between aqueous- and gas-phase chemistry suggest that oligomer formation from aldehydes is more favourable in the aqueous phase than in the gas phase.

Isoprene is the most abundant volatile organic compound with a global emission of 500-750 Tg/yr (Guenther et al., 2006). One of its principal first-generation gas phase oxidation carbonyl products is methacrolein, with a molar yield of 20-28\% (Zimmermann and Poppe, 1995; Lee et al., 2005). Besides this natural source, methacrolein is also directly emitted by anthropogenic sources (Biesenthal and Shepson, 1997). Methacrolein is largely emitted in the atmosphere, with a global emission rate higher than $100 \mathrm{Tg} / \mathrm{y}$. The atmospheric lifetime of methacrolein towards $\mathrm{OH}$-oxidation is $6-10 \mathrm{~h}$ in the gas phase (Gierczak et al., 1997), thus enabling it to encounter a cloud. Iraci et al. (1999) have estimated that only $0.02 \%$ of methacrolein enters the aqueous phase under conditions of gas-aqueous equilibrium based on the Henry's law constant $\left(5 \mathrm{M} \mathrm{atm}^{-1}\right.$ at $\left.298 \mathrm{~K}\right)$. However, ambient measurements have shown that methacrolein

Published by Copernicus Publications on behalf of the European Geosciences Union. 
Table 1. Experimental conditions and initial concentrations of reactants (1-pOH=1-propanol).

\begin{tabular}{l|l|l|l|l|l|l|l}
\hline Exp. type & Exp. number & $\begin{array}{l}{\left[\mathrm{H}_{2} \mathrm{O}_{2}\right]_{0}} \\
(\mathrm{M})\end{array}$ & $\begin{array}{l}{[\mathrm{MACR}]_{0}} \\
(\mathrm{M})\end{array}$ & $\begin{array}{l}{[1-\mathrm{pOH}]_{0}} \\
(\mathrm{M})\end{array}$ & $T\left({ }^{\circ} \mathrm{C}\right)$ & Duration & $\mathrm{pH}$ \\
\hline kinetics & 1,2 & $8.0 \times 10^{-3}$ & $5.0 \times 10^{-5}$ & $1.0 \times 10^{-4}$ & 6 & \\
\hline $\begin{array}{l}\text { Reaction } \\
\text { products A }\end{array}$ & $\mathrm{a}, \mathrm{b}, \mathrm{c}$ & $6.0 \times 10^{-2}$ & $4.0 \times 10^{-4}$ & & & \\
\hline $\begin{array}{l}\text { Reaction } \\
\text { products B }\end{array}$ & $\mathrm{d}, \mathrm{e}, \mathrm{f}, \mathrm{g}$ & \multirow{2}{*}{0.40} & $5.0 \times 10^{-3}$ & - & 25 & $11-19 \mathrm{~h}$ & free \\
\cline { 2 - 4 } & $\mathrm{h}, \mathrm{i}$ & & $2.0 \times 10^{-3}$ & & & & \\
\hline
\end{tabular}

water concentrations exceed its Henry's law predicted concentrations by two orders of magnitude (van Pinxteren et al., 2005). Thus, in addition to its transfer from the gas phase, methacrolein may also appear into the aqueous phase by other sources.

Aqueous-phase kinetics of methacrolein towards ozone (Pedersen and Sehested, 2001; Zhu and Chen, 2005; Chen et al., 2008), $\mathrm{NO}_{3}$ (Umschlag et al., 1997, 1999), and $\mathrm{OH}$ radicals at $293 \mathrm{~K}$ (Buxton et al., 2000) have been investigated. However, no mechanistic study of $\mathrm{OH}$-oxidation of methacrolein in the aqueous phase has been made to date.

The aim of this study is to elucidate the atmospheric fate of methacrolein towards $\mathrm{OH}$ radicals within the aqueous phase. We present a laboratory study of the kinetic and reaction products formed during the $\mathrm{OH}$-initiated oxidation of methacrolein under simulated atmospheric water droplet conditions.

\section{Experimental section}

OH-oxidation of methacrolein was studied in an aqueous phase photoreactor described in detail in Monod et al. (2000, 2005). Briefly, it is a $450 \mathrm{~mL}$ Pyrex thermostated reactor, equipped with an irradiation source (Xenon arc lamp (300 W; Oriel), or MSI (575 W, Phillips)), which has an irradiance spectrum comparable to the one of the sun at the earth's ground level. $\mathrm{OH}$ radicals were produced by $\mathrm{H}_{2} \mathrm{O}_{2}$ photolysis. A Pyrex filter was employed to remove the UV irradiation below $300 \mathrm{~nm}$, thus avoiding direct photolysis of methacrolein which was controlled through an experiment of direct photolysis of $4.10^{-3} \mathrm{M}$ of methacrolein (with no $\mathrm{H}_{2} \mathrm{O}_{2}$ ) during $29 \mathrm{~h}$. It was also verified that the reaction of $4.10^{-3} \mathrm{M}$ of methacrolein towards $0.4 \mathrm{M}$ of $\mathrm{H}_{2} \mathrm{O}_{2}$ in the dark during $24 \mathrm{~h}$ did not degrade significantly methacrolein.

\subsection{Kinetic experiments}

The kinetic rate constant of OH-oxidation of methacrolein was determined at $6^{\circ} \mathrm{C}$ using the relative kinetic method. This method is based on the measure of the decay rate of $\mathrm{OH}-$ induced oxidation of the reactant methacrolein (MACR) rel- atively to a reference compound (R) for which $\mathrm{OH}$-oxidation rate constant is well known.

$\mathrm{MACR}+\mathrm{OH} \stackrel{k_{\mathrm{MACR}}}{\longrightarrow}$ products

$\mathrm{R}+\mathrm{OH} \stackrel{k_{\mathrm{R}}}{\longrightarrow}$ products

where $k_{\mathrm{MACR}}$ and $k_{\mathrm{R}}$ are the rate constants of $\mathrm{OH}$-oxidation of methacrolein and $\mathrm{R}$, respectively. Therefore, the kinetic equation can be written as follows:

$\ln \left(\frac{[\mathrm{MACR}]_{0}}{[\mathrm{MACR}]_{t}}\right)=\frac{k_{\mathrm{MACR}}}{k_{\mathrm{R}}} \times \ln \left(\frac{[\mathrm{R}]_{0}}{[\mathrm{R}]_{t}}\right)$

whith $[\mathrm{MACR}]_{0},[\mathrm{MACR}]_{t},[\mathrm{R}]_{0},[\mathrm{R}]_{t}$, the concentrations of the reactant and the reference compound at times 0 and $t$, respectively. Plotting $\ln \left(\frac{[\mathrm{MACR}]_{0}}{[\mathrm{MACR}]_{t}}\right)$ versus $\ln \left(\frac{[R]_{0}}{[R]_{t}}\right)$ yields a linear curve with slope equal to $k_{\mathrm{MACR}} / k_{\mathrm{R}}$ and an intercept equal to zero. In this study, 1-propanol was chosen as the reference compound, with $k_{\mathrm{R}}=2.7( \pm 0.7) \times 10^{9} \mathrm{M}^{-1} \mathrm{~s}^{-1}$ at $6^{\circ} \mathrm{C}$ (Monod et al., 2005). Two kinetic experiments were performed (Table 1).

\subsection{Reaction products experiments}

In order to investigate the reactions products, nine experiments were performed: three type A, and six type B - Table 1. During the course of the reaction, at periodic intervals, an aliquot of $4 \mathrm{~mL}$ was sampled from the photoreactor prior to chemical analysis.

\subsection{Analytical determinations}

Aqueous phase carbonyl compounds were derivatized with 2,4-DNPH at room temperature for at least $6 \mathrm{~h}$, then analysed by HPLC-UV at $360 \mathrm{~nm}$. The HPLC-UV (Kontron) device was equipped with a $20 \mu \mathrm{L}$ injection loop, and reversed phase $\mathrm{C}_{18}$ pre-column and column (Uptisphere $\mathrm{C}_{18}, 10 \times 4 \mathrm{~mm}, 5 \mu \mathrm{m} \mathrm{ODB}$, and Alltima $\mathrm{C}_{18}$, $250 \times 4.6 \mathrm{~mm}, 5 \mu \mathrm{m}$, Alltech, Interchim, respectively) thermostated at $32^{\circ} \mathrm{C}$. A binary eluent $\left(\mathrm{H}_{2} \mathrm{O}: \mathrm{CH}_{3} \mathrm{CN}\right)$ was used at $1 \mathrm{~mL} \mathrm{~min}^{-1}$, with $\mathrm{H}_{2} \mathrm{O}: \mathrm{CH}_{3} \mathrm{CN}=60 \%: 40 \%$ for $25 \mathrm{~min}$, evolved to $0 \%: 100 \%$ from $25 \mathrm{~min}$ to $45 \mathrm{~min}$, then evolved 
Table 2. Calibration of each compound with each analytical technique. The detection limits represent 3 times the background signal.

\begin{tabular}{|c|c|c|c|c|}
\hline Compound & $\begin{array}{l}\text { Analytical } \\
\text { Technique }\end{array}$ & $\begin{array}{l}\text { Statistical error } \\
( \pm 2 \sigma) \%\end{array}$ & Experiment & $\begin{array}{r}\text { Detection } \\
\text { limit }(\mathrm{M})\end{array}$ \\
\hline 1-propanol & GC-FID & 10 & 1,2 & $1 \times 10^{-6}$ \\
\hline Methacrolein & $\begin{array}{l}\text { HPLC-UV } \\
\text { GC-FID } \\
\text { ESI-MS } \\
\text { On-line ESI-MS }\end{array}$ & $\begin{array}{l}8.6 \\
10 \\
34.0 \\
22\end{array}$ & $\begin{array}{l}1,2, \mathrm{a}, \mathrm{b}, \mathrm{c}, \mathrm{d}, \mathrm{f} \\
1,2, \mathrm{~g} \\
\text { a,b,c,d,e,g } \\
\mathrm{h}, \mathrm{i}\end{array}$ & $\begin{array}{l}1.4 \times 10^{-7} \\
1.0 \times 10^{-5} \\
7.1 \times 10^{-6} \\
2.5 \times 10^{-5}\end{array}$ \\
\hline Formaldehyde & HPLC-UV & 4.7 & $\mathrm{a}, \mathrm{b}, \mathrm{c}, \mathrm{d}, \mathrm{f}$ & $5.0 \times 10^{-8}$ \\
\hline Methylglyoxal & HPLC-UV & 9.0 & $\mathrm{a}, \mathrm{b}, \mathrm{c}, \mathrm{d}, \mathrm{f}$ & $5.0 \times 10^{-8}$ \\
\hline Hydroxyacetone & $\begin{array}{l}\text { GC-FID } \\
\text { ESI-MS } \\
\text { On-line ESI-MS }\end{array}$ & $\begin{array}{l}15 \\
22.7 \\
19\end{array}$ & $\begin{array}{l}\mathrm{g} \\
\mathrm{a}, \mathrm{b}, \mathrm{c}, \mathrm{d}, \mathrm{e}, \mathrm{g} \\
\mathrm{h}, \mathrm{i}\end{array}$ & $\begin{array}{l}6.0 \times 10^{-6} \\
2.7 \times 10^{-6} \\
2.0 \times 10^{-5}\end{array}$ \\
\hline $\begin{array}{l}\text { Acetate/Acetic } \\
\text { acid }\end{array}$ & $\begin{array}{l}\text { ESI-MS } \\
\text { On-line ESI-MS }\end{array}$ & $\begin{array}{l}28.6 \\
13\end{array}$ & $\begin{array}{l}\text { a,b,c,d,e,g } \\
\mathrm{h}, \mathrm{i}\end{array}$ & $\begin{array}{l}3.3 \times 10^{-6} \\
2.0 \times 10^{-5}\end{array}$ \\
\hline Pyruvate & $\begin{array}{l}\text { ESI-MS } \\
\text { On-line ESI-MS }\end{array}$ & $\begin{array}{l}25.6 \\
18\end{array}$ & $\begin{array}{l}\mathrm{a}, \mathrm{b}, \mathrm{c}, \mathrm{d}, \mathrm{e}, \mathrm{g} \\
\mathrm{h}, \mathrm{i}\end{array}$ & $\begin{array}{l}1.1 \times 10^{-6} \\
3.0 \times 10^{-7}\end{array}$ \\
\hline Oxalate & $\begin{array}{l}\text { ESI-MS } \\
\text { On-line ESI-MS }\end{array}$ & $\begin{array}{l}23.5 \\
32\end{array}$ & $\begin{array}{l}\mathrm{a}, \mathrm{b}, \mathrm{c}, \mathrm{d}, \mathrm{e}, \mathrm{g} \\
\mathrm{h}, \mathrm{i}\end{array}$ & $\begin{array}{l}2.2 \times 10^{-6} \\
1.0 \times 10^{-6}\end{array}$ \\
\hline Glyoxylate & $\begin{array}{l}\text { ESI-MS } \\
\text { On-line ESI-MS }\end{array}$ & $\begin{array}{l}25.0 \\
16\end{array}$ & $\begin{array}{l}\mathrm{a}, \mathrm{b}, \mathrm{c}, \mathrm{d}, \mathrm{e}, \mathrm{g} \\
h, i\end{array}$ & $\begin{array}{l}1.4 \times 10^{-6} \\
1.0 \times 10^{-6}\end{array}$ \\
\hline $\begin{array}{l}\text { Methacrylate/ } \\
\text { Methacrylic acid }\end{array}$ & $\begin{array}{l}\text { ESI-MS } \\
\text { On-line ESI-MS }\end{array}$ & $\begin{array}{l}26.1 \\
20\end{array}$ & $\begin{array}{l}\mathrm{a}, \mathrm{b}, \mathrm{c}, \mathrm{d}, \mathrm{e}, \mathrm{g} \\
\mathrm{h}, \mathrm{i}\end{array}$ & $\begin{array}{l}5.8 \times 10^{-7} \\
1.0 \times 10^{-6}\end{array}$ \\
\hline
\end{tabular}

to $60 \%: 40 \%$ from $45 \mathrm{~min}$ to $50 \mathrm{~min}$, and then lasted isocratic for $10 \mathrm{~min}$.

GC-FID (HP serie II 5890) was used to analyze oxygenated organic compounds (such as 1-propanol, methacrolein and hydroxyacetone). It was equipped with a semi-polar capillary column (HP INNOWAX $15 \mathrm{~m} \times 0.25 \mathrm{~mm} \times 0.50 \mu \mathrm{m})$ which allowed us to inject aqueous phase samples. An internal standard $(10 \mu \mathrm{L}$ of 1 -butanol at $0.1 \mathrm{M}$ ) was added to each sample of $1000 \mu \mathrm{L}$ prior to injection. The GC injector and detector were heated at $250^{\circ} \mathrm{C}$. Helium gas was used as carrier gas at $1.2 \mathrm{~mL} \mathrm{~min}^{-1}$, with a $1 / 5$ split. The oven temperature program was $40^{\circ} \mathrm{C}$ for $4 \mathrm{~min}$, $10^{\circ} \mathrm{C} \mathrm{min}^{-1}$ up to $120^{\circ} \mathrm{C}, 120^{\circ} \mathrm{C}$ for $5 \mathrm{~min}, 40^{\circ} \mathrm{C} \mathrm{min}^{-1}$ up to $240^{\circ} \mathrm{C}$, and $240^{\circ} \mathrm{C}$ for $5 \mathrm{~min}$.

Aqueous phase carboxylic acids and polyfunctional species were analyzed by ESI-MS and ESI-MS/MS. The instrument is a triple quadrupole mass spectrometer (Varian 1200L), equipped with an electrospray ionisation chamber (ESI). Samples and standard solutions were directly introduced into the ESI source at a flow rate of $25 \mu 1 \mathrm{~min}^{-1}$. The full-scan mass spectrum of the sample solutions were recorded every hour during the experiment. In order to avoid sample storage, two experiments ( $h$ and i) were performed by directly coupling the aqueous phase photoreactor with the ESI-MS-MS (Table 2), according to Poulain et al. (2007).
Additionally to prevent contamination, this technique, operated continuously during the reaction (about $20 \mathrm{~h}$ ), allowed us to obtain much more precise time profiles for reactants and oxidation products (see results).

For experiments a, b, c, d, e, g, h and i, ESI-MS and ESI-MS/MS analysis were performed in both positive and negative modes with capillary voltage of $+40 \mathrm{~V}$ and $-40 \mathrm{~V}$, respectively, over the mass range of 30-1000 amu. Nitrogen served as the drying gas at a pressure of 15 PSI in both positive and negative modes. The nebulizing gases, air and nitrogen (at 60 PSI) in the negative and the positive mode respectively, were held at $350^{\circ} \mathrm{C}$. During MS/MS experiments, argon was used as the collision gas and was delivered at a pressure of 2 mTorr. MS/MS collision energy was between 5 and $20 \mathrm{~V}$ depending on the compounds. This instrument was used to quantify the aqueous phase concentrations of polyfunctional molecules. Methacrylic, pyruvic, glyoxylic, and oxalic acids were analyzed in the ESI-MS negative mode, and methacrolein, hydroxyacetone and acetic acid were analyzed in the ESI-MS positive mode. Quantification of these compounds was conducted on the basis of mixed standard solutions, using the same instrumental conditions as the sample analysis described above. Statistical error limits and detection limits of the calibration for each compound (in the range covering the concentrations 


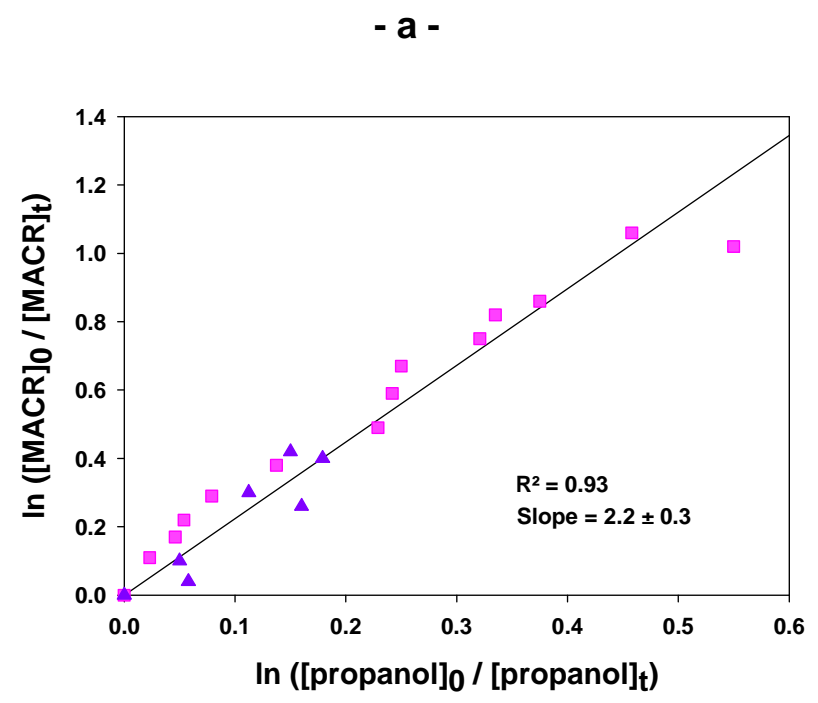

$-\mathbf{b}$ -

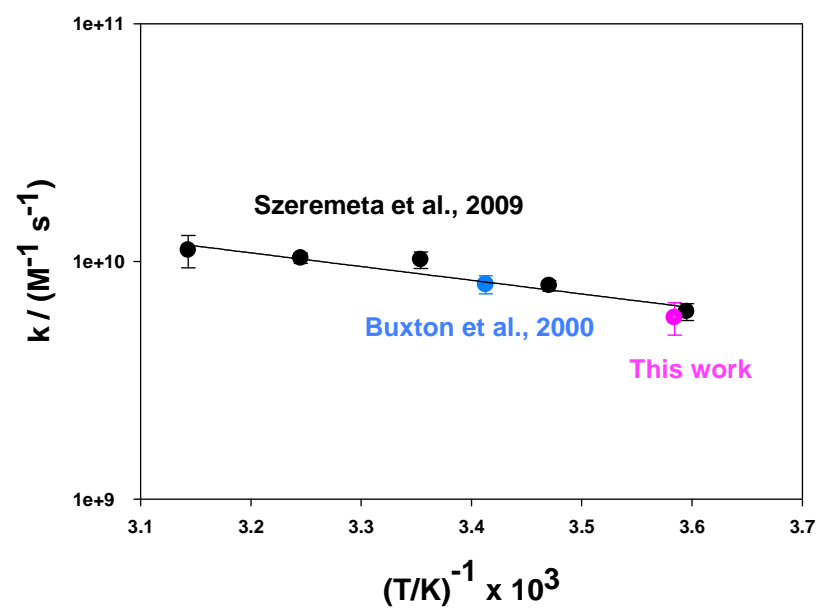

Fig. 1. (a) Kinetics of $\mathrm{OH}$-oxidation of methacrolein in the aqueous phase relative to 1-propanol at $6^{\circ} \mathrm{C}$ in unbuffured solutions. Experiments 1 and 2 (squares and triangles) are reported here. The uncertainty of the slope was calculated using the method developed by Brauers and Finlayson-Pitts (1997), taking into account both the standard deviation on the linear fit and the analytical uncertainties of methacrolein and 1-propanol. Indicated errors are $2 \times \sigma$. (b) Rate constants of $\mathrm{OH}$-oxidation of methacrolein as a function of temperature: comparison between the values obtained by Szeremeta et al. (2009) at $\mathrm{pH}=7$ (black), Buxton et al. (2000) at pH=4 (blue) and this work at "free $\mathrm{pH}$ " (pink).

encountered in the experiments) are summarized in Table 2. Additionally, some suspected polyfunctional oxidation products were quantified using standards whose chemical structures are similar: 2,3-dihydroxy-2-methylpropanal (DHMP) and 2-hydroxy-2-methylmalonaldehyde (HMM) were quan- tified using standards of methacrolein and hydroxyacetone whereas peroxymethacrylic acid (PMA) was quantified using standards of methacrylic acid.

\section{Results}

\subsection{Kinetics of $\mathrm{OH}-0 x i d a t i o n$ of methacrolein in the aqueous phase}

A very good agreement between experiments 1 and 2 was obtained (Fig. 1a). Taking into account the $k_{\mathrm{R}}$ value, we

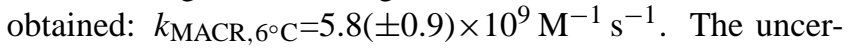
tainty was taken as twice the standard deviation on the linear regression, calculated taking into account errors on both abscissa and ordinate scales using the program developped by Brauers and Finlayson-Pitts (1997). This rate constant, obtained at "free $\mathrm{pH}$ ", shows a very good agreement with the previous determinations by Buxton et al. (2000) (at $\mathrm{pH}=4$ ) and Szeremeta et al. (2009) (at pH=7) (Fig. 1b). The values obtained show that the rate of $\mathrm{OH}$-oxidation of methacrolein is high, near the diffusion limit. Compared to the rate constants of $\mathrm{C}_{2}-\mathrm{C}_{5}$ saturated aldehydes (which range from 2 to $4 \times 10^{9} \mathrm{M}^{-1} \mathrm{~s}^{-1}$, Monod et al., 2005), the obtained $k_{\mathrm{MACR}}$ is significantly higher, thus suggesting that $\mathrm{OH}$-oxidation mainly proceeds by addition on the $\mathrm{C}=\mathrm{C}$ bond. Moreover, the value of $k_{\mathrm{MACR}}$ is in good agreement with those reported for other unsaturated aldehydes, namely: crotonaldehyde and acrolein, with $k_{\text {crotonaldehyde, } 20^{\circ} \mathrm{C}}=5.8 \times 10^{9} \mathrm{M}^{-1} \mathrm{~s}^{-1}$ and $k_{\text {acrolein, } 20^{\circ} \mathrm{C}}=7.0 \times 10^{9} \mathrm{M}^{-1} \mathrm{~s}^{-1}$ (Lilie and Henglein, 1970). This further supports the notion that, for unsaturated aldehydes, the mechanism of $\mathrm{OH}$-oxidation should mainly proceed via a fast addition on the $\mathrm{C}=\mathrm{C}$ bond. This is in good agreement with Buxton et al. (2000) who observed the formation of $\mathrm{OH}$-adducts during the $\mathrm{OH}$-oxidation of methacrolein in the aqueous phase. Furthermore, the Arrhenius parameters, obtained from the data compiled in Fig. 1b were used to calculate the free Gibbs energy $\left(\Delta G^{\neq}\right)$ of $\mathrm{OH}$-oxidation of methacrolein. The obtained value $\left(\Delta G^{\neq}=16.0 \pm 3.5 \mathrm{~kJ} \mathrm{~mol}^{-1}\right)$ is slightly lower than those determined by previous studies for saturated compounds (Monod et al., 2005; Gligorovski and Herrmann, 2004; Ervens et al., 2003). This result may provide further evidence for a faster $\mathrm{OH}$-attack mechanism than the $\mathrm{H}$-abstraction one.

\subsection{Reaction products of $\mathrm{OH}$-oxidation of methacrolein in the aqueous phase}

The formation of eight reaction products was observed, including methylglyoxal, formaldehyde, hydroxyacetone, acetic, methacrylic, oxalic, glyoxylic, and pyruvic acids (Fig. 2). Figure 2 shows that an excellent agreement was obtained between experiments performed in the same conditions: this is illustrated for methacrolein and several oxidation products by the excellent agreement between experiments $\mathrm{h}$ (grey) and $\mathrm{i}$ (white), and between experiments a 

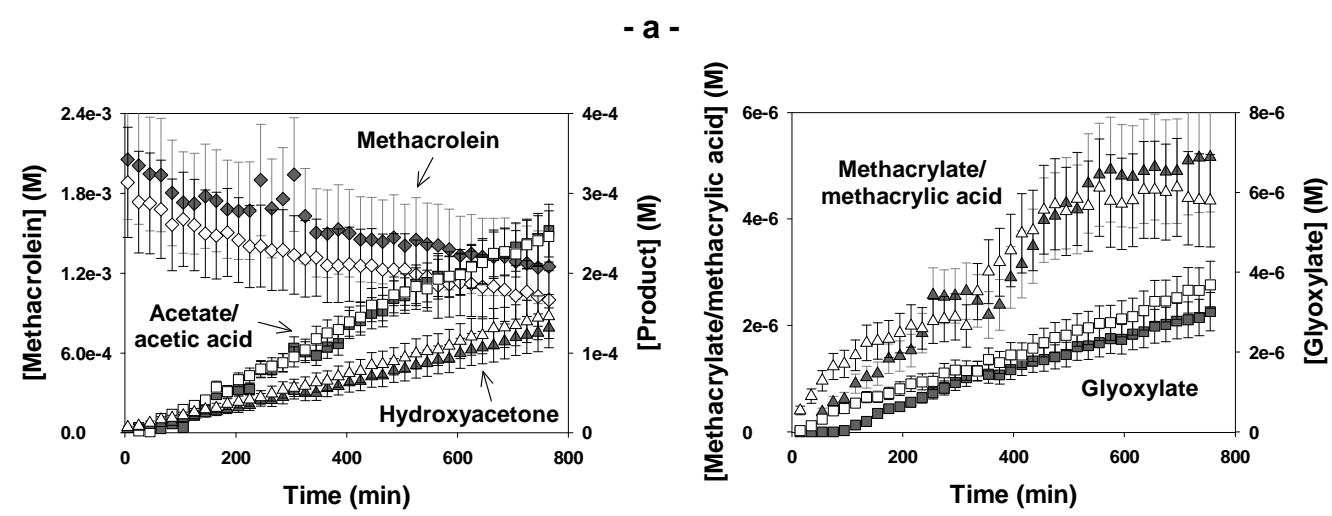

- b -
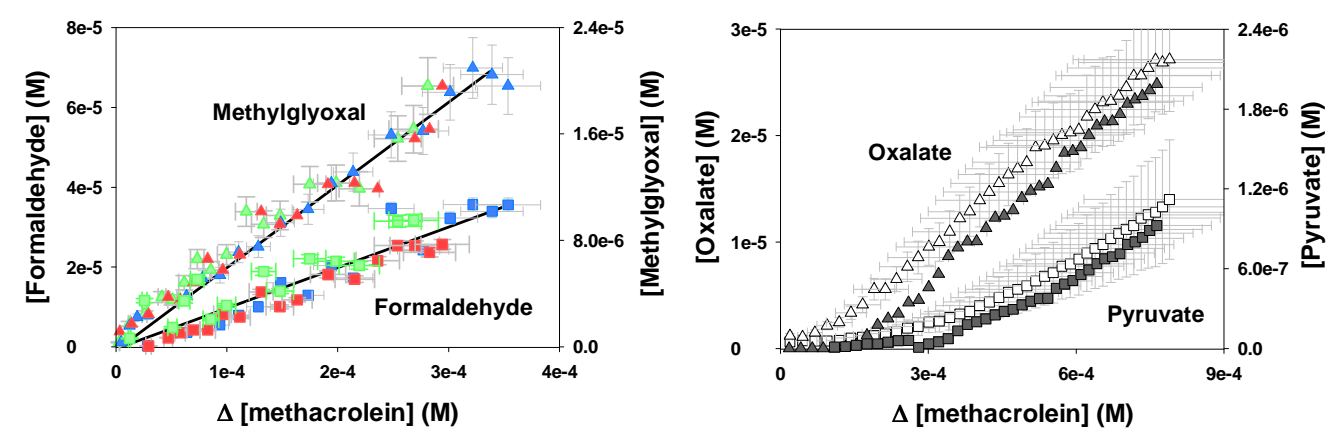

Fig. 2. Concentrations of methacrolein and its reaction products during $\mathrm{OH}$-oxidation of methacrolein at $25^{\circ} \mathrm{C}$ in unbuffured solution (experiments a=blue, $\mathrm{b}=$ red and $\mathrm{c}=$ green, $\mathrm{h}=$ grey and $\mathrm{i}=$ white). (a) Time profiles; (b) Reaction products' yields: $\Delta$ [methacrolein] is the consumed concentration of methacrolein.

(blue), $\mathrm{b}$ (red) and c (green). The $\mathrm{pH}$ of the unbuffered solution, which started at 5.6, decreased down to 4.5 due to the formation of the organic acids, thus indicating the aging of the solution. Due to their low $\mathrm{pK}_{a}(<4.2)$, the observed acids were in their ionic form, except for methacrylic/methacrylate and acetic/acetate ( $\mathrm{pK}_{a}=4.7$ for both) for which both neutral and ionic forms were present. Among the major reaction products, hydroxyacetone, acetic acid/acetate, methylglyoxal and formaldehyde (Fig. 2b) were primary reaction products (i.e. first generation reaction products, formed directly without other intermediate molecular reaction products). Methacrylic acid/methacrylate was both a primary and a secondary reaction product. The time profile of the latter shows that it also reacts rapidly during the course of the reaction (Fig. 2a), certainly due to the fast reaction of $\mathrm{OH}$ by addition on the $\mathrm{C}=\mathrm{C}$ bond. Glyoxylate, oxalate and pyruvate (Fig. $2 \mathrm{a}$ and $\mathrm{b}$ ) were secondary products (i.e. second generation reaction products, formed via the reaction of primary reaction products). The very small quantity of pyruvate observed can be due to its fast reactivity towards direct photolysis in addition to $\mathrm{OH}$-oxidation (Guzmán et al., 2006; Altieri et al., 2006; Carlton et al., 2007). Finally, using the ESI-MS/MS identification technique, the formation of four polyfunctional compounds was observed, namely peroxymethacrylic acid (PMA), 2- hydroxy-2-methylmalonaldehyde (HMM), 2,3-dihydroxy2-methylpropanal (DHMP), and 2,3-dihydroxymethacrylic acid (DHMA). Their identifications are explained hereafter.

- 2-hydroxy-2-methylmalonaldehyde (HMM: $102 \mathrm{~g} / \mathrm{mol}$ ) was detected in the positive mode at $m / z 103^{+}$amu. As we have verified with commercial hydroxypropanedial which has the same chemical structure (except for a methyl group), after ionisation, the fragmentation of HMM can occur either on the carbonyl function, or on the alcohol one, thus explaining the major daughter ions observed in the MS/MS spectrum (Fig. 3a).

- Peroxymethacrylic acid (PMA: $102 \mathrm{~g} / \mathrm{mol}$ ) was detected in the negative mode at $\mathrm{m} / \mathrm{z} 101^{-}$amu. This peak was intense, and its intensity as a function of consumed MACR clearly showed a primary behaviour (Fig. 3c). The MS/MS fragmentation of this peak produced one neutral loss of 44, thus denoting the presence of an acid function. After ionisation, the fragmentation of this peak gave exactly the same spectrum as the one obtained with a standard of synthesized PMA (Fig. 3b).

- 2,3-dihydroxy-2-methylpropanal (DHMP: $104 \mathrm{~g} / \mathrm{mol}$ ) was detected in the negative mode at $\mathrm{m} / \mathrm{z} 103^{-}$amu. As we have verified with commercial glyceraldehyde 

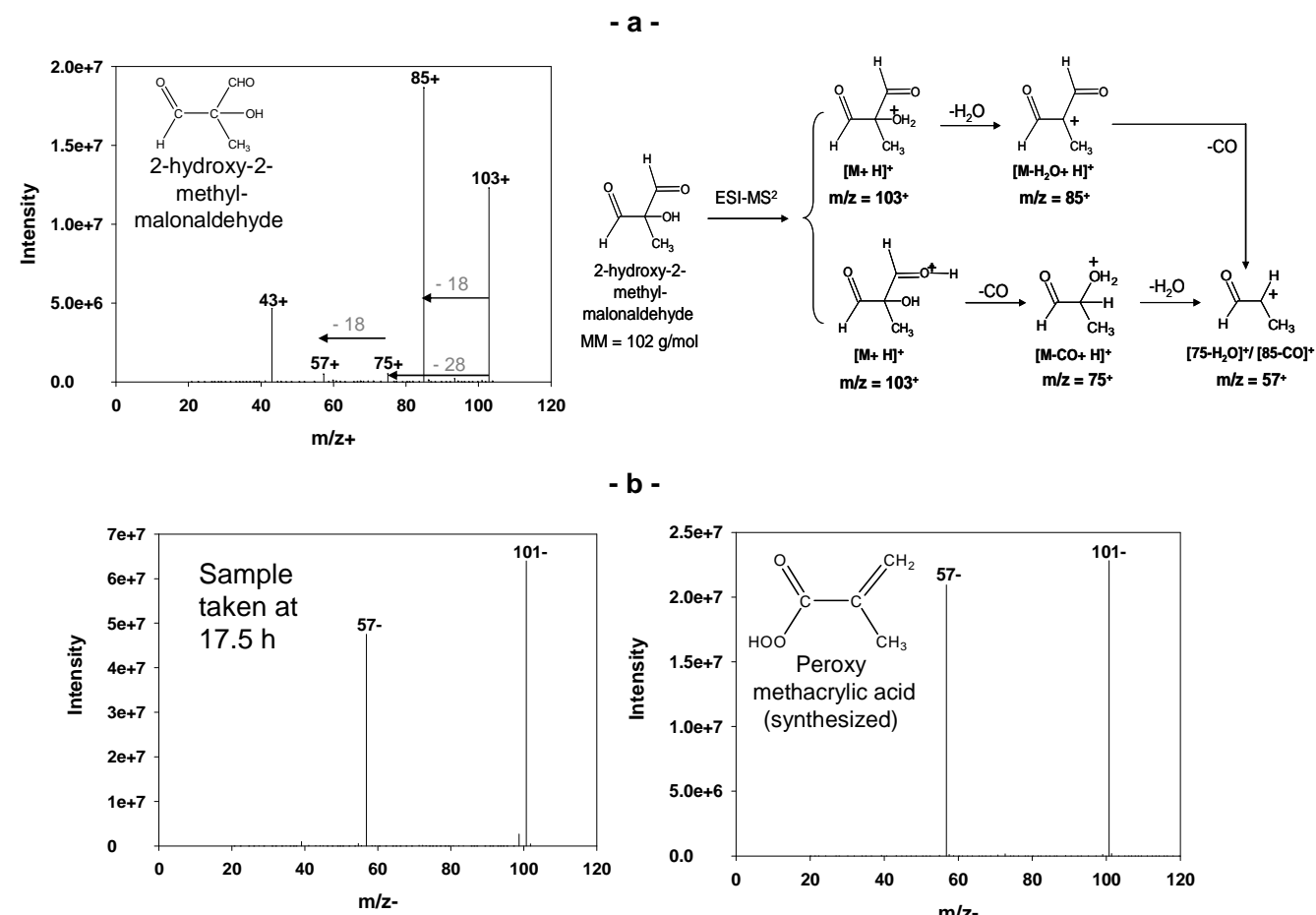

- b -
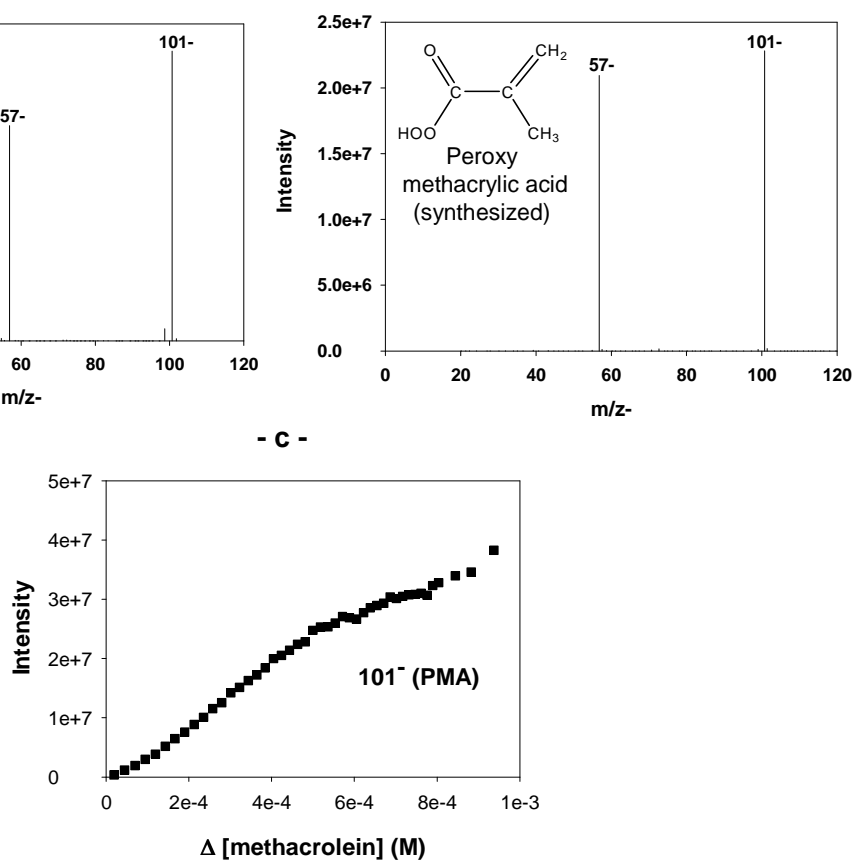

Fig. 3. Identification of 2-hydroxy-methylmalonaldehyde (HMM) and peroxymethacrylic acid (PMA) during the course of the reaction. (a) HMM was identified by ESI-MS/MS fragmentation mechanism (collision energy $=8 \mathrm{eV}$ on a sample taken after $16 \mathrm{~h}$ of reaction). (b) PMA was identified by comparison of the ESI-MS/MS fragments of a sample (taken after $17.5 \mathrm{~h}$ of reaction) to those of the synthesized molecule (with a $8 \mathrm{eV}$ collision Energy for both); (c) intensity of peak 101- (PMA) (obtained by on-line ESI-MS) as a function of consumed methacrolein during $14 \mathrm{~h}$ of reaction. The synthesis of PMA consisted of mixing $250 \mu 1$ of pure methacrylic acid with $250 \mu 1$ of $\mathrm{H}_{2} \mathrm{O}_{2}(50 \%)$ and $125 \mu$ l of pure acetic acid for 10 days.

which has the same chemical structure (except for a methyl group), after ionisation, the fragmentation of DHMP can occur either on the carbonyl function, or on the alcohol one, thus explaining the major daughter ions observed in the MS/MS spectrum (Fig. 4a). The OH-oxidation of DHMP leads to the formation of 2,3dihydroxymethacrylic acid (DHMA)

- 2,3-dihydroxymethacrylic acid (DHMA: $120 \mathrm{~g} / \mathrm{mol}$ ) was detected in the negative mode at $m / z 119^{-}$amu. After ionisation, the fragmentation of this peak gave exactly the same spectrum as the one obtained with a standard of synthesized DHMA (Fig. 4b), using the proto- col of Claeys et al. (2004b). The intensities of peaks $103^{-}$(DHMP) and 119- (DHMA) as a function of consumed MACR clearly shows that they correspond respectively to a primary and a secondary reaction product (Fig. 4c), in good agreement with the proposed mechanism (Fig. 5). It can be noted that DHMA was previously identified in ambient aerosols (Claeys et al., 2004a; Ion et al., 2005) and as a major reaction product of the oxidation by $\mathrm{H}_{2} \mathrm{O}_{2}$ of methacrylic acid in aqueous solution acidified with formic acid (Claeys et al.,2004b). 

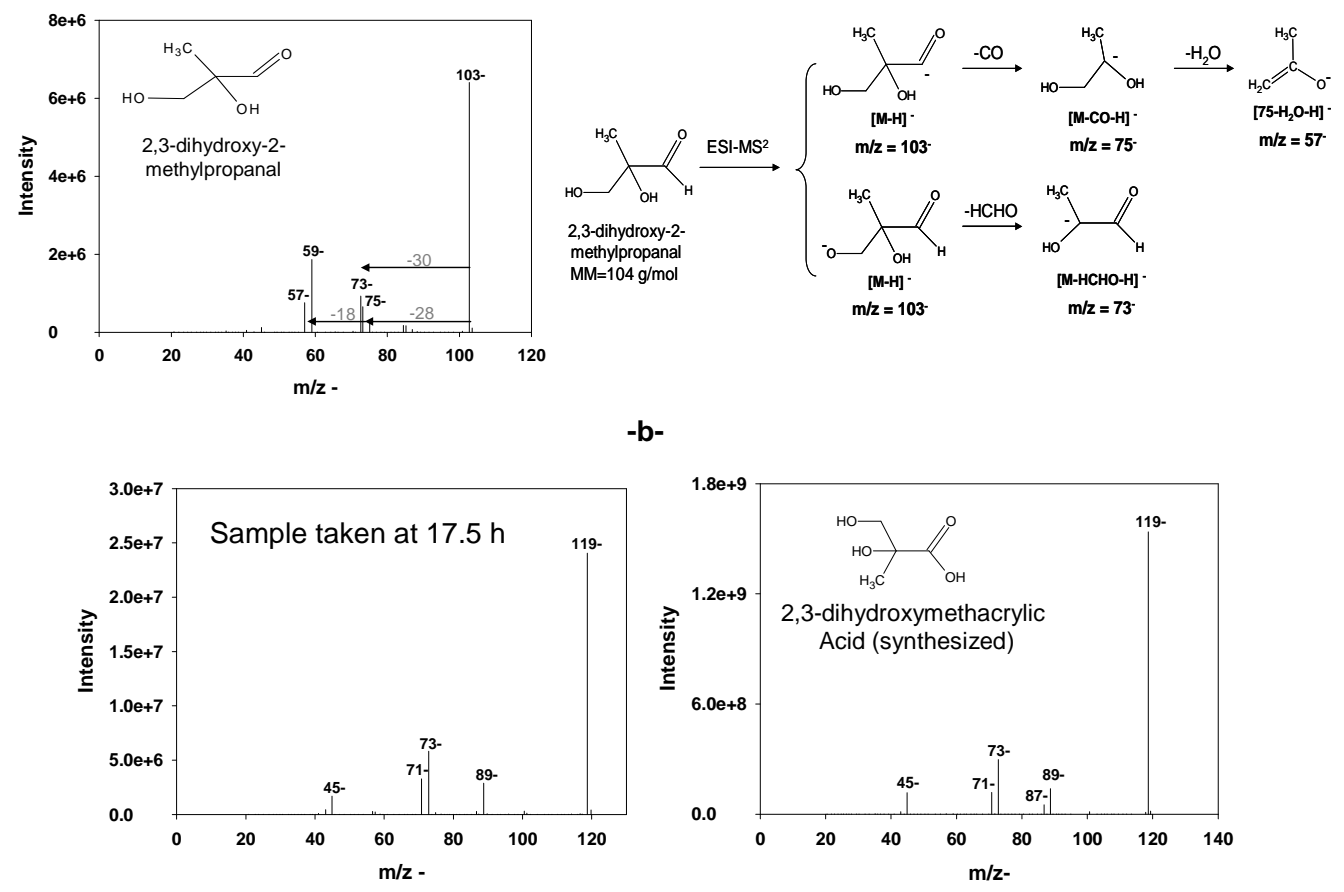

-b-
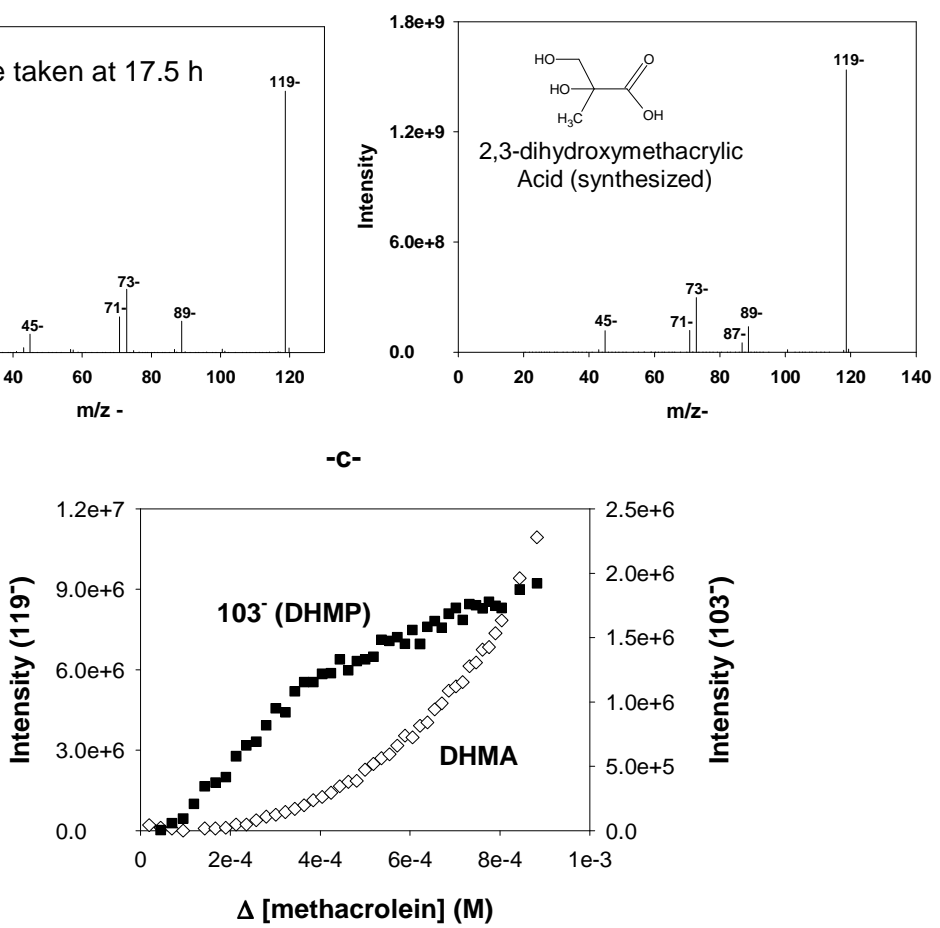

Fig. 4. Identifications of 2,3-dihydroxy-2-methylpropanal (DHMP) and 2,3-dihydroxymethacrylic acid (DHMA). (a) DHMP was identified as the most probable product (in the absence of standards) by ESI-MS/MS (with a $8 \mathrm{eV}$ collision Energy on a sample taken after $17.5 \mathrm{~h}$ of reaction); (b) DHMA was identified by comparison of the ESI-MS/MS fragments of a sample (taken after $17.5 \mathrm{~h}$ of reaction) to those of the synthesized molecule (with a $10 \mathrm{eV}$ collision Energy for both); (c) DHMP (103-) and DHMA (119-) intensities as a function of consumed methacrolein during $14 \mathrm{~h}$ of reaction (obtained by on-line ESI-MS).

We have verified that the peaks (at $\mathrm{m} / \mathrm{z} 101^{-}, 103^{+}$, $103^{-}$and $119^{-}$) corresponding to the four above mentioned molecules were not present in a standard mixture containing the quantified reaction products, even at high concentrations (i.e. methacrolein $\left(3 \times 10^{-3} \mathrm{M}\right)$, hydroxyacetone, methylglyoxal, formaldehyde, acetic and formic acid $\left(6 \times 10^{-4} \mathrm{M}\right)$, methacrylic acid, pyruvic acid, glyoxylic acid and oxalic acid $\left(3 \times 10^{-5} \mathrm{M}\right)$. This shows that the observed formation of PMA, HMM, DHMP and DHMA was not an analytical artefact occurring during the electrospray ionisation, (i.e. adducts formed in the ionisation chamber by the combination of smaller molecules).

\section{Discussion}

\subsection{Mechanism of $\mathrm{OH}-0 x i d a t i o n$ of methacrolein in the aqueous phase}

As with most short chain aldehydes, methacrolein is able to hydrate in the aqueous phase (Melichercik and Treindl, 1981) (Reaction R1).<smiles>C=C(C)C=O</smiles> 


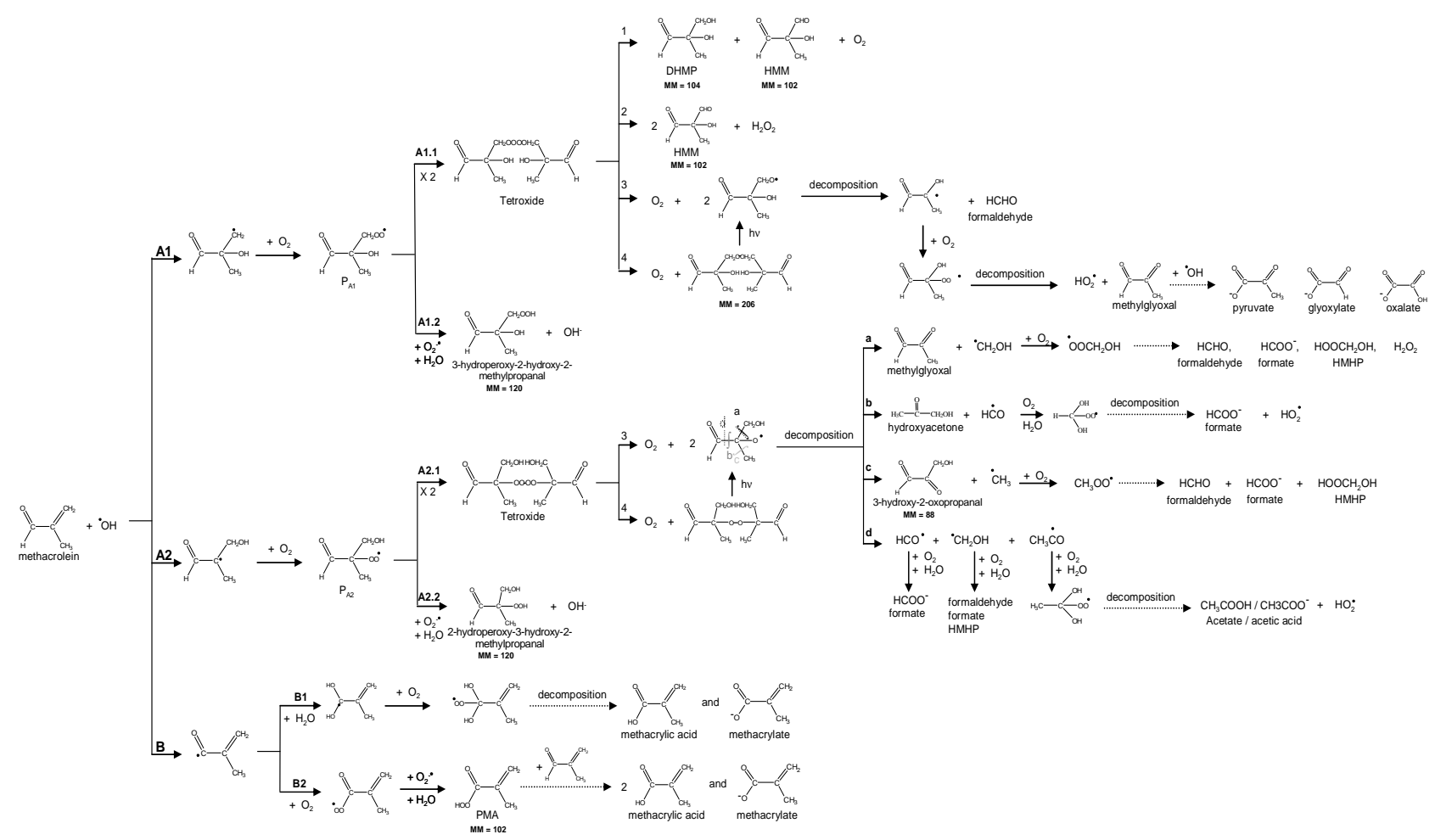

Fig. 5. Chemical mechanism of the three main pathways for the $\mathrm{OH}$-initiated oxidation of methacrolein in the aqueous phase. DHMP=2,3dihydroxy-2-methylpropanal; HMM=2-hydroxy-2-methylmalonaldehyde; PMA=peroxymethacrylic acid; MM=Molecular mass.

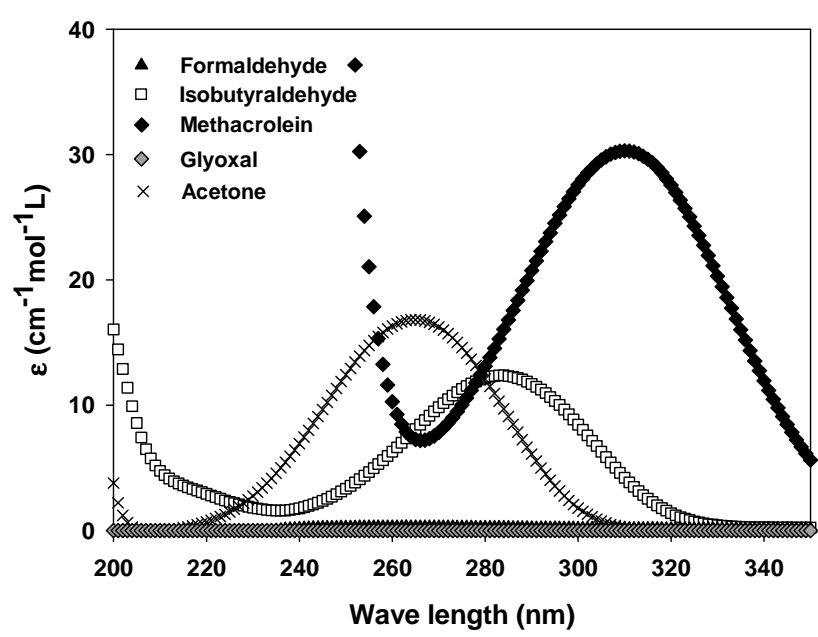

Fig. 6. Molar extinction coefficients in the UV-visible for carbonyl compounds compared to that of methacrolein in the aqueous phase.

However, its hydration equilibrium constant has not been experimentally determined to date (to our knowledge). In the aqueous phase, carbonyl groups absorb UV light in the region $200-350 \mathrm{~nm}$. Carbonyl compounds that are known to be totally hydrated in the aqueous phase, such as formaldehyde and glyoxal, do not absorb in this region (Fig. 6). Methacrolein shows a strong absorption with a maximum at
$311 \mathrm{~nm}$, comparable to that of acetone, which hydration constant is as low as 0.0014 (Guthrie et al., 2000). Compared to isobutyraldehyde $\left(\mathrm{K}_{\mathrm{hyd}}=0.5-0.6\right.$ (Bell et al., 1966; Guthrie et al., 2000), the absorbance of methacrolein is more intense. This may be due to a mesomeric effect between the $\mathrm{C}=\mathrm{C}$ and $\mathrm{C}=\mathrm{O}$ bonds in methacrolein, which prevents hydration. Finally, based on the method developed by Hilal et al. (2005) the SPARC on-line calculator (SPARC on-line v4.2) evaluates the hydration constant of methacrolein to 0.046 . For all these reasons, we assumed that methacrolein is mainly in its carbonyl form in the aqueous phase.

As mentioned earlier, $\mathrm{OH}$-oxidation of methacrolein can proceed via addition on the $\mathrm{C}=\mathrm{C}$ bond (pathway A) (Fig. 5). We also consider here the $\mathrm{H}$-abstraction of the carbonyl function (pathway B). The external addition of $\mathrm{OH}$ (A2) is more likely than the internal addition (A1), because i) it leads to a tertiary radical, which is more stable than the primary radical formed in pathway $\mathrm{A} 1$, and ii) the internal addition of $\mathrm{OH}$ (A1) generates more steric hindrance than the external one (A2) (Buxton et al., 2000). The H-abstraction on the methyl group is not presented here because no reaction product associated with it was detected: this pathway is certainly of minor importance compared to the three others (Buxton et al., 2000; Herrmann, 2003; Monod and Doussin, 2008). Hereafter are presented and discussed the three possible pathways presented in Fig. 5. 


\subsubsection{Pathway A: $\mathrm{OH}$-addition on the $\mathrm{C}=\mathrm{C}$ bond}

\section{Pathway A1: internal addition}

The internal addition of $\mathrm{OH}$ leads to the formation of an alkyl radical, which rapidly adds to dissolved oxygen to form a peroxy radical $\left(\mathrm{P}_{\mathrm{A} 1}\right)$ which can react following two different pathways:

Pathway A1.1: radical $\mathrm{P}_{\mathrm{A} 1}$ reacts with itself to form an unstable tetroxide which rapidly decomposes to form different reaction products through pathways A1.11, 12, 13, and 14 (von Sonntag and Schuchmann, 1997). DHMP and HMM were observed as primary reaction products in good agreement with pathways A1.11 and 12. The peroxide formed in pathway A1.14 contains a weak O-O bond which is sensitive to UV-Visible radiation. This compound was not detected: it is thus likely that, under our experimental conditions, its photolysis undergoes a homolytic break of the $\mathrm{O}-\mathrm{O}$ bond leading to the alkoxy radical formed via pathway A1.13. This alkoxy radical can further decompose to form formaldehyde and methyglyoxal as primary reaction products in good agreement with our observations (Fig. 2). The obtained molar yields for DHMP+HMM were $10.1 \pm 5.2 \%$ with standards of methacrolein, and $4.1 \pm 2.0 \%$ with standards of hydroxyacetone. We can thus deduce a branching ratio for pathways A1.11+A1.12 ranging from 3 to $11 \%$.

Pathway A1.2: radical $\mathrm{P}_{\mathrm{A} 1}$ can also react with $\mathrm{O}_{2}^{-}$to form the corresponding hydroperoxide (Docherty et al., 2005). However, the latter was not detected in our experiments.

\section{Pathway A2: external addition}

The external addition of $\mathrm{OH}$ leads to the formation of an alkyl radical, which rapidly adds to dissolved oxygen to form another peroxy radical $\left(\mathrm{P}_{\mathrm{A} 2}\right)$.

Pathway A2.1: radical $\mathrm{P}_{\mathrm{A} 2}$ reacts with itself to form an unstable tetroxide. Due to the absence of $\mathrm{H}$ in $\alpha$ position, this tetroxide can decompose through only two different pathways (A2.13 and 14). The peroxide formed through pathway A2.14 was not detected in our experiments, it is thus likely that it was photolyzed under our experimental conditions, leading to the alkoxy radical formed through pathway A2.13. This alkoxy radical undergoes $\beta$-decomposition via pathways A2.13a, b, and d (von Sonntag and Schuchmann, 1997) to form formaldehyde, hydroxymethylhydroperoxide (HMHP), formate (Monod et al., 2000, 2007) and methyglyoxal as primary reaction products (channel A2.13a); hydroxyacetone and formate (Mc Elroy and Waygood, 1991) as primary reaction products (channel A2.13b) and acetic acid/acetate, formaldehyde, formate and HMHP (channel A2.13d). Although this last pathway requires a number of simultaneous bond breaks, a special attention was paid to it, because it was the only one that could explain the formation of acetic acid/acetate observed in our experiments. Radical $\mathrm{CH}_{3} \mathrm{C}=\mathrm{O}$ hydrates in the aqueous phase $\left(\mathrm{K}_{\text {hyd }}=2.10^{4} \mathrm{~s}^{-1}\right)$ faster than $\mathrm{O}_{2}$ addition (Schuchmann and von Sonntag, 1988), leading to a diol radical, which undergoes $\mathrm{O}_{2}$ addition, and eliminates $\mathrm{HO}_{2}$ to form acetic acid/acetate. Pathway A2.13c was considered to be a minor process because 3-hydroxy-2-oxopropanal has not been detected in our experiments.

All the reaction products obtained through pathways A2.13a, b, and d are in good agreement with our experiments, except formate and HMHP which were not measured.

Pathway A2.2: radical $\mathrm{P}_{\mathrm{A} 2}$ can also react with $\mathrm{O}_{2}^{-}$to form the corresponding hydroperoxide. However, the latter was not detected in our experiments.

\subsubsection{Pathway B: OH-attack by hydrogen abstraction on the carbonyl function}

This pathway leads to the formation of a $\alpha$-carbonyl radical which may hydrate through pathway B1, leading to methacrylic acid as primary reaction product. However, the time profile of methacrylic acid/methacrylate (Fig. 2) shows a singular behaviour which can represent both a primary and a secondary reaction product (explained in Sect. 3.2). It is probable that the hydration of the $\alpha$-carbonyl radical is slow because of the mesomeric effect between the $\mathrm{C}=\mathrm{C}$ and the $\mathrm{C}=\mathrm{O}$ bonds which stabilises the radical, thus enabling the addition of $\mathrm{O}_{2}$, through pathway $\mathrm{B} 2$. This reaction leads to the formation of a peroxycarbonyl radical. Schuchmann and von Sonntag (1988) found that an analogous radical formed from non hydrated acetaldehyde was found to react towards $\mathrm{O}_{2}^{-}$, to form peroxyacetic acid. Extrapolating these findings to our compound, it is probable that pathway B2 leads to the formation of peroxymethacrylic acid (PMA) as a primary reaction product (Fig. 3c), in good agreement with our observations. Furthermore, Schuchmann and von Sonntag (1988) have shown that peroxyacetic acid slowly reacts with non hydrated acetaldehyde to yield acetic acid, under experimental conditions similar to ours. It is thus probable that PMA slowly reacts with methacrolein to form methacrylic acid. This explains the observed formation of methacrylic acid as a secondary reaction product.

PMA represents only pathway B2. This compound was quantified using standards of methacrylic acid whose structure is very similar. The resulting branching ratio for pathway $\mathrm{B} 2$ is $4.1 \pm 2.6 \%$. Therefore, taking into account the yield of methacrylic acid, we deduced a branching ratio for pathway $\mathrm{B}(=\mathrm{B} 1+\mathrm{B} 2)$ of $4.8 \pm 3.0 \%$. This low branching ratio confirms that $\mathrm{H}$-abstraction by $\mathrm{OH}$ on the carbonyl function of methacrolein is of minor importance compared to the $\mathrm{OH}$ addition on the $\mathrm{C}=\mathrm{C}$ bond.

The mechanism shown in Fig. 5 explains the formation of methylglyoxal, formaldehyde, hydroxyacetone, acetic acid/acetate, DHMP, HMM and PMA as primary reaction products, and methacrylic acid/methacrylate as a primary and a secondary reaction product, as observed in our experiments (Table 3). Most of these reaction products are 
Table 3. Molar yields and total carbon yield during the $\mathrm{OH}$-oxidation of methacrolein in the aqueous phase for all the experiments (described in Table 1).

\begin{tabular}{|c|c|c|c|c|c|}
\hline \multirow[b]{2}{*}{ Reaction products } & \multicolumn{2}{|c|}{ Molar yields $(\%)^{\mathrm{a}}$} & \multicolumn{3}{|c|}{ Total carbon yield (\%) } \\
\hline & $\begin{array}{l}\text { Exp. A } \\
a, b, c\end{array}$ & $\begin{array}{l}\text { Exp. B } \\
\text { d, e, f, g, h, i }\end{array}$ & $\begin{array}{l}\text { Exp. A } \\
a, b, c\end{array}$ & $\begin{array}{l}\text { Exp. B } \\
\text { d, e, f, g, h, i }\end{array}$ & $\begin{array}{l}\text { Exp. } B^{b} \\
\text { d, e, f, g, h, i }\end{array}$ \\
\hline Methylglyoxal & $6.0 \pm 1.2$ & $9.1 \pm 1.7$ & \multirow{5}{*}{$21.4 \pm 9.5$} & \multirow{5}{*}{$30.3 \pm 9.8$} & \multirow{7}{*}{$25-57$} \\
\hline Formaldehyde & $10.2 \pm 1.0$ & $12.2 \pm 1.7$ & & & \\
\hline Hydroxyacetone & $9.8 \pm 5.5$ & $15.0 \pm 6.2$ & & & \\
\hline Acetic acid/acetate & $8.7 \pm 5.4$ & $17.0 \pm 6.0$ & & & \\
\hline $\begin{array}{l}\text { Methacrylic } \\
\text { acid/methacrylate }\end{array}$ & $\begin{array}{l}2.6 \pm 1.6 \\
\text { (and secondary) }\end{array}$ & $\begin{array}{l}0.7 \pm 0.4 \\
\text { (and secondary) }\end{array}$ & & & \\
\hline HMM + DHMP & not measured & $3-11 \%^{\mathrm{c}}$ & & & \\
\hline PMA & not measured & $4.1 \pm 2.6 \% \mathrm{c}$ & & & \\
\hline $\begin{array}{l}\text { Pyruvate } \\
\text { Oxalate } \\
\text { Glyoxylate } \\
\text { DHMA }\end{array}$ & \multicolumn{5}{|c|}{ Secondary products } \\
\hline
\end{tabular}

${ }^{\text {a }}$ Uncertainties take into account the analytical uncertainties of both the reaction products and the consumed methacrolein. The values reported for Exp A are the means of experiments a, b and c. The values reported for Exp B are the means of experiments d, e, f, $g, h$ and i.

$\mathrm{b}$ Total carbon yield taking into account the estimated formation yields for HMM, DHMP and PMA.

${ }^{\mathrm{c}}$ Estimated formation yields based on standards of other compounds, with similar chemical structure (see text).

highly reactive towards $\mathrm{OH}$ radicals, and can be oxidized under our experimental conditions to form secondary products. For example, the aqueous phase $\mathrm{OH}$-oxidation of one of the major products, methylglyoxal, is relatively fast $\left(k_{\mathrm{OH} 25^{\circ} \mathrm{C}}=5.3( \pm 0.4) \times 10^{8} \mathrm{M}^{-1} \mathrm{~s}^{-1}\right.$ Monod et al., 2005), and leads to the formation of pyruvate, glyoxylate and oxalate (Altieri et al., 2008). This can explain the formation of these three reaction products observed as secondary products in our experiments (Fig. 2 and Table 3).

The comparison between the branching ratios observed in the aqueous phase and those known for the gas phase oxidation of methacrolein via $\mathrm{OH}$ gives some interesting information on the mechanism of the first step OH-attack. The branching ratio of the hydrogen abstraction pathway (B) is only $4.8 \pm 3.0 \%$ in the aqueous phase while it is between 45 and 50\% in the gas phase (Pimentel and Arbilla, 1999; Orlando et al., 1999; Chuong and Stevens, 2004). This difference can be explained by the findings of Mellouki et al. (2003) and Smith and Ravishankara (2002) who proposed that, in the gas phase, $\mathrm{OH}$ radicals form strong hydrogen bonds with the carbonyl groups. Compared to the direct hydrogen abstraction pathway, these hydrogen bonds lower the activation energy of the reaction, and increase its kinetics. In the aqueous phase, hydrogen bonds between water and oxygenated groups may inhibit the formation of the hydrogenbonded complexes between $\mathrm{OH}$ radicals and oxygenated organic compounds (Monod et al., 2005). Therefore, pathway $\mathrm{B}$ is doped in the gas phase compared to the aqueous phase. As a consequence, the reaction products are very different in the two phases.

\subsection{Carbon balance}

The molar yield of the primary reaction products was determined by plotting their concentration versus the concentration of consumed methacrolein at the same reaction time (Fig. 2). The slope of the linear regression gives the molar yield of each product. For each primary reaction product $(i)$, the carbon yield was determined by Eq. (2).

carbon yield $(i)=\frac{n_{C}(i)}{4} \times m_{y}(i)$

Where: $n_{C}(i)$ is the number carbon atoms of product $i$, and $\mathrm{m}_{y}(i)$ is the molar yield of product $i$. Finally the total carbon yield was calculated from the sum of the carbon yields of each quantified primary reaction product. The molar yields obtained for all the experiments are summarized in Table 3, together with the total carbon yields. The comparison between experiment type A and B shows a good agreement, thus indicating that initial concentrations do not significantly influence the yields. However, taking into account the estimated formation yields of HMM+DHMP and DMA, the total carbon yield ranges between 25 and $57 \%$, thus indicating that a large part of the reaction products is missing.

Formate and HMHP were not measured in our experiments, and their detection limits (with ESI/MS) are too high to establish an experimental upper limit. Therefore using the mechanism (Fig. 5), we have evaluated an upper limit for their yields: 
- Formate is formed through pathways A2.13a, b, c and d. Assuming that pathways A2.2 and A1 are of minor importance compared to A2.1, one can estimate an upper limit for the molar yield of formate of $95 \%$ (taking into account a yield for pathway B of $4.8 \%$ ).

- HMHP is formed through pathways A2.13a and c and $\mathrm{d}$, after the evolution of $\mathrm{CH}_{2} \mathrm{OH}$ radicals, which were shown to form HMHP and formate with a ratio of $\frac{[\text { HMHP] }}{\text { Formic/Formate] }}=\frac{1.5}{9}$ (Monod et al., 2007). Thus, one can estimate an upper limit for the molar yield of HMHP of $95 \% \times 1.5 / 9=16 \%$.

The estimated upper limit for the molar yields of formate and HMHP added to the experimental carbon yields reported in Table 3 result in an upper limit for the total carbon yield ranging from 53 to $85 \%$. This shows that a part of the reaction products remain still unidentified. The formation of higher molecular weight compounds as primary reaction products have been observed, and are presented in El Haddad et al. (2009). These non quantified molecules and oligomers may explain the lack of carbon. These molecules can also explain the formation of Secondary Organic Aerosol (SOA) which was experimentally observed (El Haddad et al., 2009). These findings indicate that multiphase photooxidation of methacrolein may be an important precursor of SOA in the atmosphere.

\section{Conclusions}

The photooxidation of methacrolein was studied in the aqueous phase under simulated cloud droplet conditions. The obtained rate constant of $\mathrm{OH}$-oxidation of methacrolein at $6^{\circ} \mathrm{C}$ in unbuffered solutions was $5.8( \pm 0.9) \times 10^{9} \mathrm{M}^{-1} \mathrm{~s}^{-1}$. The measured rate coefficient is consistent with $\mathrm{OH}$-addition on the $\mathrm{C}=\mathrm{C}$ bond. The reaction products obtained at $25^{\circ} \mathrm{C}$ in unbuffered solutions were methylglyoxal, formaldehyde, hydroxyacetone, acetic acid/acetate, 2,3-dihydroxy2-methylpropanal, 2-hydroxy-2-methylmalonaldehyde and peroxymethacrylic acid as primary reaction products. Methacrylic acid/methacrylate was observed as both primary and secondary reaction product. Pyruvate, oxalate, glyoxylate and 2,3-dihydroxymethacrylic acid were detected as secondary reaction products. A chemical mechanism was proposed for the OH-oxidation of methacrolein and the calculation of the branching ratios confirmed that the $\mathrm{OH}$-addition on the $\mathrm{C}=\mathrm{C}$ bond is of major importance (higher than 95\%) compared to the other pathways. An upper limit for the total carbon yield was estimated to range from 53 to $85 \%$, indicating that some reaction products remain unidentified. A possible source of this mismatch is the formation of higher molecular weight compounds as primary reaction products which are presented in El Haddad et al. (2009).
Acknowledgements. This study was funded by the French PNLEFE-CHAT (Programme National-Les Enveloppes Fluides et l'Environnement-Chimie Atmosphérique), by the Provence-AlpesCôte-d'Azur Region, and by the French ERICHE network.

Edited by: V. F. McNeill

\section{References}

Altieri, K. E., Seitzinger, S. P., Carlton, A. G., Turpin, B. J., Klein, G. C., and Marshall, A. G.: Oligomers formed through in-cloud méthylglyoxal reactions : Chemical composition, properties, and mechanisms investigated by ultra-high resolution FT-ICR mass spectrometry, Atmos. Environ, 42, 1476-1490, 2008.

Altieri, K. E., Carlton, A. G., Lim, H. J., Turpin, B. J., and Seitzinger, S. P.: Evidence for Oligomer Formation in Clouds: Reactions of Isoprene Oxidation Products, Environ. Sci. Technol., 40, 4956-4960, 2006.

Bell, R. P.: The reversible hydration of carbonyl compounds, in: Advances in physical organic chemistry, edited by: Gold, V., Academic press London and New York, 1-27, 1966.

Biesenthal, T. A. and Shepson, P. B.: Observations of anthropogenic inputs of the isoprene oxidation products methyl vinyl ketone and methacrolein to the atmosphere, Geophys. Res. Lett. 24, 13751378, 1997.

Brauers, T. and Finlayson-Pitts, B. J.: Analysis of relative rate measurements, Int. J. Chem. Kinet., 29, 665-672, 1997.

Buxton, G. V., Salmon, G. A., and Williams, J. E.: The reactivity of biogenic monoterpenes towards $\mathrm{OH}$ and $\mathrm{SO}_{4}^{-}$radicals in Deoxygenated acidic solution, J. Atmos. Chem., 36, 111-134, 2000.

Carlton, A. G., Turpin, B. J., Altieri, K. E., Seitzinger, S., Reff, A., Lim, H. J., and Ervens, B.: Atmospheric oxalic acid and SOA production from glyoxal: results of aqueous photooxidation experiments, Atmos. Environ., 41, 7588-7602, 2007.

Chen, Z. M., Wang, H. L., Zhu, L. H., Wang, C. X., Jie, C. Y., and Hua, W.: Aqueous-phase ozonolysis of methacrolein and methyl vinyl ketone: a potentially important source of atmospheric aqueous oxidants, Atmos. Chem. Phys., 8, 2255-2265, 2008, http://www.atmos-chem-phys.net/8/2255/2008/.

Chuong, B. and Stevens, P. S.: Measurements of the kinetics of the $\mathrm{OH}$-Initiated oxidation of methyl vinyl ketone and methacrolein Inc., Int. J. Chem. Kinet., 36, 12-25, 2004.

Claeys, M., Graham, B., Vas, G., Wang, W., Vermeylen, R., Pashynska, V., Cafmeyer, J., Guyon, P., Andreae, M., Artaxo, P., and Maenhaut, W.: Formation of secondary organic aerosols through photooxidation of isoprene, Science, 303, 1173-1176, 2004a.

Claeys, M., Wang, W., Ion, A. C., Kourtchev, I., Gelencsér, A., and Maenhaut, W.: Formation of secondary organic aerosols from isoprene and its gas-phase oxidation products through reaction with hydrogen peroxide, Atmos. Environ., 38, 4093-4098, 2004b.

Docherty, K. S., Wu, W., Lim, Y. B., and Ziemann, P. J.: Contributions of Organic Peroxides to Secondary Aerosol Formed from Reactions of Monoterpenes with $\mathrm{O}_{3}$, Environ. Sci. Technol, 39, 4049-4059, 2005.

El Haddad, I., Liu, Yao, Nieto-Gligorovski, L., Michaud, V., Temime-Roussel, B., Quivet, E., Marchand, N., Sellegri, K., and Monod, A.: In-cloud processes of methacrolein under simulated conditions - Part 2: Formation of secondary organic aerosol, At- 
mos. Chem. Phys., 9, 5107-5117, 2009,

http://www.atmos-chem-phys.net/9/5107/2009/.

Ervens, B., Gligorovski, S., and Herrmann, H.: Temperaturedependent rate constants for hydroxyl radical reactions with organic compounds in aqueous solutions, Phys. Chem. Chem. Phys., 5, 1811-1824, 2003.

Gierczak, T., Burkholder, J. B., Talukdar, R. K., Mellouki, A., Barone, S. B., and Ravishankara, A. R.: Atmospheric fate of methyl vinyl ketone and methacrolein, J. Photoch. Photobio. A, 110, 1-10, 1997.

Gligorovski, S. and Herrmann, H.: Kinetics of reactions of $\mathrm{OH}$ with organic carbonyl compounds in aqueous solution, Phys. Chem. Chem. Phys., 6, 4118-4126, 2004.

Guenther, A., Karl, T., Harley, P., Wiedinmyer, C., Palmer, P. I., and Geron, C.: Estimates of global terrestrial isoprene emissions using MEGAN (Model of Emissions of Gases and Aerosols from Nature), Atmos. Chem. Phys., 6, 3181-3210, 2006, http://www.atmos-chem-phys.net/6/3181/2006/.

Guthrie, J. P.: Hydration of Carbonyl Compounds, an Analysis in Terms of Multidimensional Marcus Theory, J. Am. Chem. Soc., 122, 5529-5538, 2000.

Guzmán, M. I., Colussi, A. I., and Hoffmann, M. R.: Photoinduced oligomerization of aqueous pyruvic acid, J. Phys. Chem. A, 110, 3619-3626, 2006.

Herrmann, H.: Kinetics of aqueous phase reactions relevant for atmospheric chemistry, Chem. Rev., 103, 4691-4716, 2003.

Hilal, S. H., Bornander, L. L., Carreira, L. A., and Karickhoff, S. W.: Hydration equilibrium constants of aldehydes, ketones and quinazolines, QSAR Comb. Sci., 24, 631-638, 2005.

Ion, A. C., Vermeylen, R., Kourtchev, I., Cafmeyer, J., Chi, X., Gelencsér, A., Maenhaut, W., and Claeys, M.: Polar organic compounds in rural $\mathrm{PM}_{2.5}$ aerosols from K-puszta, Hungary, during a 2003 summer field campaign: Sources and diel variations, Atmos. Chem. Phys., 5, 1805-1814, 2005,

http://www.atmos-chem-phys.net/5/1805/2005/.

Iraci, L. T., Baker, B. M., Tyndall, G. S., and Orlando, J. J.: Measurements of the Henry's Law coefficients of 2-methyl-3-buten2-ol, methacrolein, and methylvinyl ketone, J. Atmos. Chem., 33, 321-330, 1999.

Lee, W., Baasandorj, M., Stevens, P. S., and Hites, R. A.: Monitoring $\mathrm{OH}-$ Initiated Oxidation Kinetics of Isoprene and Its Products Using Online Mass Spectrometry, Environ. Sci. Technol., 39, 1030-1036, 2005.

Lelieveld, J. and Crutzen, P. J.: The role of clouds in tropospheric photochemistry, J. Atmos. Chem., 12, 229-267, 1991.

Lilie, J. and Henglein, A.: Pulse radiolytic study of unsaturated carbonyl compound oxidation in aqueous solution. Hydrated enols as intermediates, Ber. Bunsen-Ges., 74, 388-393, 1970.

Mc Elroy, W. J. and Waygood, S. J.: Oxidation of formaldehyde by the hydroxyl radical in aqueous solution, J. Chem. Soc. Faraday T., 87, 1513-1521, 1991.

Melichercik, M. and Treindl, L.: Kinetics and mechanism of the oxidation of acrolein, crotonaldehyde, and methacrolein with cerium(IV) sulphate, Chem. Zvesti, 35, 153-63, 1981.

Mellouki, A., Le Bras, G., and Sidebottom, H.: Kinetics and mechanisms of the oxidation of oxygenated organic compounds in the gas phase, Chem. Rev., 103, 5077-5096, 2003.

Michaud, V., El Haddad, I., Liu, Yao, Sellegri, K., Laj, P., Villani, P., Picard, D., Marchand, N., and Monod, A.: In-cloud processes of methacrolein under simulated conditions - Part 3: Hygroscopic and volatility properties of the formed secondary organic aerosol, Atmos. Chem. Phys., 9, 5119-5130, 2009, http://www.atmos-chem-phys.net/9/5119/2009/.

Monod, A., Chebbi, A., Durand-Jolibois, R., and Carlier, P.: Oxidation of methanol by hydroxyl radicals in aqueous solution under simulated cloud droplet conditions, Atmos. Environ., 34, 52835294, 2000.

Monod, A., Poulain, L., Grubert, S., Voisin, D., and Wortham, H.: Kinetics of $\mathrm{OH}$-initiated oxydation of oxigenated organic compounds in the aqueous phase: new rate constants, structureactivity relationships and atmospheric implications, Atmos. Environ., 39, 7667-7688, 2005.

Monod, A., Chevallier, E., Durand-Jolibois, R., Doussin, J. F., Picquet-Varrault, B., and Carlier, P.: Photooxidation of methylhydroperoxide and ethylhydroperoxide in the aqueous phase under simulated cloud droplet conditions, Atmos. Environ., 41, 2412-2426, 2007.

Monod, A. and Doussin, J. F.: Structure-activity relationship for the estimation of $\mathrm{OH}$-oxidation rate constant of aliphatic organic compounds in the aqueous phase: alkanes, alcohols, organic acids and bases, Atmos. Environ., 42, 7611-7622, 2008.

Orlando, J. J., Tyndall, G. S., and Paulson, S. E.: Mechanism of the OH-initiated oxidation of methacrole, Geophys. Res. Lett., 26(14), 2191-2194, 1999.

Pedersen, T. and Sehested, K.: Rate constants and activation energies for ozonolysis of isoprene methacrolein and methyl-vinylketone in aqueous solution: significance to the in-cloud ozonation of isoprene, Int. J. Chem. Kinet., 33, 182-190, 2001.

Pimentel, A. S. and Arbilla, G.: Kinetic Analysis of the Gas-Phase Reactions of Methacrolein with the $\mathrm{OH}$ Radical in the Presence of $\mathrm{NO}_{\mathrm{x}}$, J. Braz. Chem. Soc., 10(6), 483-491, 1999.

Poulain, L., Monod, A., and Wortham, H.: Development of a new on-line mass spectrometer to study the reactivity of soluble organic compounds in the aqueous phase under tropospheric conditions: Application to $\mathrm{OH}$-oxidation of $\mathrm{N}$-methylpyrrolidone, J. Photoch. Photobio. A, 187, 10-23, 2007.

Schuchmann, M. N. and von Sonntag, C.: The rapid hydratation of the Acetyl Radical - A pulse radiolysis study of Acetaldehyde in aqueous solution, J. Am. Chem. Soc., 110, 5698-5701, 1988.

Smith Ian, W. M. and Ravishankara, A. R.: Role of hydrogenbonded intermediates in the bimolecular reactions of the hydroxyl radical, J. Phys. Chem. A, 106, 4798-4807, 2002.

SPARC on-line v4.2: online available at: http://ibmlc2.chem.uga. edu/sparc/, 2009.

Szeremeta, E., Barzaghi, P., Böge, O., Herrmann, H., Gmachowski, L., and Rudzinski, K. J.: Aqueous-phase reactions of isoprene oxidation products with hydroxyl radicals, in: Atmospheric composition Change - Causes and Consequences - Local to Global, edited by: Maione, M. and Fuzzi, S., Aracne editrice S.r.l., 2009.

Umschlag, T., Herrmann, H., and Zellner, R.: A kinetic study of aqueous phase nitrate $\left(\mathrm{NO}_{3}\right)$ radical reactions with aldehydes and their impact on atmospheric clouds and aerosols chemistry, PSI-Proceedings, 97-02, 47-49, 1997.

Umschlag, T., Herrmann, H., and Zellner, R.: A kinetic study of aqueous-phase reactions of the nitrate radical $\left(\mathrm{NO}_{3}\right)$ with aldehydes, Proceedings of EUROTRAC Symposium '98: Transport and Chemical Transformation in the Troposphere, GarmischPartenkirchen, Germany, 694-698, 1999. 
Van Pinxteren, D., Plewka, A., Hofmann, D., Mueller, K., Kramberger, H., Svrcina, B., Baechmann, K., Jaeschke, W., Mertes, S., Collett, J. L., and Herrmann, H.: Schmuecke hill cap cloud and valley stations aerosol characterisation during FEBUKO (II): Organic compounds, Atmos. Environ., 39, 4305-4320, 2005.

Von Sonntag, C. and Schuchmann, H. P.: Peroxyl radicals in aqueous solutions, Peroxyl Radicals The chemistry of free radicals, edited by: Wiley, J., New York, 173-234, 1997.
Warneck, P.: In-cloud chemstry opens pathway to the formation of oxalic acid in the marine atmosphere, Atmos. Environ., 37, 2423-2427, 2003.

Zhu, L. and Chen, Z.: Ozonolysis of methacrolein and methyl vinyl ketone in aqueous solutions, Huanjing Kexue, 26, 83-86, 2005.

Zimmermann, J. and Poppe, D.: A supplement for the RADM2 chemical mechanism: the photooxidation of isoprene, Atmos. Environ., 30, 1255-1269, 1995. 